\title{
AS SIMETRIAS DO MODELO HEMPELIANO DE EXPLICAÇÃO
}

Túlio Roberto Xavier de Aguiar ${ }^{1}$

RESUMO Este artigo faz um exame crítico do modelo nomológico dedutivo de Hempel. Nós focalizamos a atenção sobre certas simetrias desse modelo geradas pela exigência de condições nomicamente suficientes para uma explicação. Tais condições, argüimos, são incapazes de traduzir corretamente as relações explanatórias e causais.

Palavras-chave Hempel, Explicação, Causação, Condições Suficientes

ABSTRACT This article critically examines Hempel's deductivenomological model. We focus on the model's symmetries produced by requirements of nomic sufficient conditions for explanations. Such conditions, we argue, cannot translate correctly the explanatory and causal relations.

Keywords Hempel, Explanation, Causation, Sufficient Conditions

\section{Introdução}

Todas as teorias contemporâneas sobre explicação partem do trabalho de Hempel. Seja para aperfeiçoá-la, seja para buscar-lhe uma alternativa, a teoria hempeliana tem servido como um guia permanente para orientar qualquer

1 Professor do Departamento de Filosofia da Universidade Federal de Ouro Preto. Artigo recebido em maio de 2005 e aprovado em junho de 2005. taguiar.bh@terra.com.br.

KRITERION, Belo Horizonte, n $^{\circ}$ 111, Jun/2005, p. 138-152 
reflexão sobre a explicação científica. A seguir, faremos um exame crítico do chamado modelo nomológico-dedutivo, atentando para as simetrias que o caracterizam.

Hempel utiliza o seguinte esquema para apresentar o modelo nomológicodedutivo (N-D):

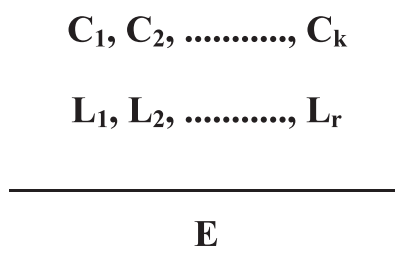

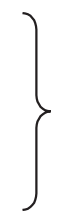

Explanans S

Explanandum

Neste esquema, $\mathbf{C}_{1}, \mathbf{C}_{2}, \ldots . . . . . . . . . \mathbf{C}_{\mathbf{k}}$ descrevem as circunstâncias particulares e $\mathbf{L}_{1}, \mathbf{L}_{2}, \ldots . . . . . . . . . \mathbf{L}_{\mathrm{r}}$ são leis gerais que suportam a explicação. $\mathrm{O}$ evento ou fato a ser explicado ou, ainda, a sentença que os descreve são designados por $\mathbf{E}$. O traço indica que estamos diante de uma dedução do explanans para o explanandum. Isso pretende expressar a idéia de que um fenômeno é explicado mostrando-se que resultou de certas circunstâncias particulares segundo certas leis. Mas de que maneira, exatamente, isso deve ser compreendido em Hempel? A seguinte passagem é crucial para compreendermos o espírito da teoria hempeliana:

(...) o argumento mostra que, dadas as circunstâncias particulares e as leis em questão, a ocorrência do fenômeno podia ser esperada; é neste sentido que a explicação permitenos compreender por que o fenômeno ocorreu (Hempel, 1965, p. 337, grifos no original).

Assim, Hempel esclarece o meio pelo qual uma explicação produz a compreensão da ocorrência de um fenômeno, evento ou aspecto de um evento, mostrando que este era expectável. Hempel considera isso como uma condição geral de adequação para qualquer explicação - que o explanans torne o explanandum expectável, se este ainda não ocorreu².

$2 \mathrm{Na}$ verdade, isso faz pleno sentido apenas para explicações causais, tal como as compreende Hempel. Nestas, as condições iniciais ou circunstâncias particulares são, temporalmente, anteriores ao potencial explanandum. Mesmo nestes casos, expectabilidade faz sentido pleno apenas quando a derivação que vai das condições iniciais (e leis) para o explanandum potencial ocorre antes deste. Nos outros casos, expectabilidade, se é que o termo pode ser mantido, teria que ser compreendida de outra forma. Talvez devêssemos falar de expectabilidade como conformidade a um cálculo. Assim, perguntaríamos "qual é o 


\section{A Tese da Simetria}

O tipo de argumento dedutivo discutido por Hempel em conexão com a explicação leva-o a enunciar a tese da identidade estrutural entre explicação e predição, também conhecida como tese da simetria. Em uma primeira expressão desta, Hempel diz:

Desde que em uma explicação N-D, completamente formulada, de um evento particular o explanans implica logicamente o explanandum, nós podemos dizer que o argumento explanatório poderia ter sido usado para uma predição dedutiva do evento-explanandum $s e$ as leis e os fatos particulares aduzidos em seu explanans tivessem sido conhecidos e considerados em um tempo oportuno. Neste sentido, uma explicação N-D é uma predição N-D em potencial (Hempel, 1965, p. 366).

O que é declarado acima constitui metade da tese da simetria: toda explicação adequada é potencialmente uma predição. A outra metade diz que "toda predição adequada constitui potencialmente uma explicação". Assim, explicação e predição, segundo Hempel, possuem estrutura lógica idêntica, divergindo apenas quanto aos aspectos pragmáticos, como o que é conhecido e o que é procurado, e das relações temporais entre os eventos contidos no explanans e no explanandum e destas com o tempo em que a derivação ocorre. Em uma explicação, o eventoexplanandum é conhecido e buscamos as leis e os fatos particulares que permitam deduzi-lo. Já no caso de uma predição, atentamos para as leis e os fatos particulares e deduzimos o evento antes de sua ocorrência. A primeira subtese é de fundamental importância para Hempel a ponto de ele asseverar que ela é suportada por um princípio mais geral que constitui uma "condição geral de adequação para qualquer explicação racionalmente aceitável de um evento particular". Ele enuncia esta condição assim:

Qualquer resposta racionalmente aceitável à questão "Por que o evento X ocorreu?" deve oferecer informação que mostra que $X$ podia ser esperado — se não com certeza, como no caso de uma explicação N-D, então pelo menos com razoável probabilidade (Hempel, 1965, p. 367-368).

\footnotetext{
valor de $\mathrm{x}$, dado o valor de y e as leis pertinentes?", onde a realização de x é temporalmente anterior à realização de y. Esperamos que o valor do cálculo corresponda ao que efetivamente ocorreu, lembrando que o que ocorreu pode ser conhecido (por exemplo, através de relatos históricos) ou não. Um exemplo concreto seria o de um astrônomo que calcula a posição de um planeta no passado através de sua posição atual. Podemos pensar também em exemplos nos quais três variáveis inter-relacionadas têm seus valores realizados simultaneamente. Neste caso, nós esperamos que o valor de qualquer uma delas, obtido através de derivação a partir das outras duas, seja o que acontece na realidade. Note-se que, também neste caso, a realização dos valores das variáveis pode estar no presente, passado ou futuro. Muitas combinações são possíveis entre as relações temporais dos itens que constituem o explanans e o explanadum e entre estes e o tempo da derivação.
} 
Várias objeções foram apresentadas a cada uma das subteses. Em relação à primeira delas, Scriven protagonizou críticas acerbas ao modelo hempeliano. Consideremos primeiro o caso em que temos leis estatísticas ${ }^{3} .25 \%$ das pessoas que contraem sífilis, não tratadas com penicilina, desenvolvem paresia. Se perguntarmos por que uma pessoa sofre de paresia, a resposta parece ser o fato de que ela foi vítima de sífilis não tratada com penicilina (apud Salmon, 1998, p. 309-310). Neste caso, entretanto, os fatos contidos no explanans - que a sífilis não tratada se associa regularmente com paresia em $25 \%$ dos casos e que determinada pessoa foi vitimada por sífilis - não permitem uma predição razoável do explanandum - o desenvolvimento de paresia por uma pessoa específica. É claro que alguém imbuído de uma fé determinista pode dizer que leis estatísticas refletem apenas o nosso estado de ignorância e que a investigação posterior poderia revelar alguma outra característica, ao lado da sífilis não tratada, que restauraria o nosso poder preditivo. Poderíamos, assim, saber, com certeza, quais indivíduos desenvolveriam paresia. Evidentemente, paga-se um alto preço por pressupor, sem investigação empírica, a verdade do determinismo.

Hempel é sensível aos achados da teoria quântica que parecem indicar que as leis do mundo microfísico são irredutivelmente estatísticas. Ele prefere, neste caso, dizer que as condições nomicamente necessárias para um evento não são explanatórias (Hempel, 1965, p. 369). Assim, ele evita pressupor que o mundo é determinístico. Um exemplo devido a Salmon ajudará a compreender ainda melhor a situação. Suponhamos uma moeda altamente viciada na proporção de $95 \%$ para caras e $5 \%$ para coroas. Se lançamos a moeda e obtemos cara, poderíamos construir uma explicação dentro do modelo hempeliano à medida que este evento pode ser racionalmente esperado, dada a informação contida no explanans. Se, entretanto, obtivéssemos uma coroa, já não poderíamos predizer este evento, dado o explanans (Salmon et al., 1992, p. 29). Para Hempel, apenas um evento altamente provável pode ser explicado. A questão, aqui, é que, em ambos os casos, compreendemos o mecanismo envolvido igualmente bem. Parece pouco natural restringir nossa capacidade explanatória apenas a eventos que são altamente prováveis, dado o explanans. ${ }^{4}$

3 Nestes casos, o modelo hempeliano recebe o nome de modelo indutivo-estatístico. O modelo indutivoestatístico e o modelo nomológico-dedutivo recebem o nome genérico de modelo legiforme de cobertura. Nos dois casos, o explanandum pode ser racionalmente esperado com certeza ou com uma alta probabilidade, sendo fundamental a identificação de uma explicação com uma predição em potencial.

4 O princípio que parece operar aqui, e que remonta a Platão, é que a mesma coisa não pode explicar opostos (ver SALMON, 1998, p. 326; RUBEN, 1990, p. 56). 
Um exemplo de natureza diversa, também devido a Scriven, coloca o seguinte problema: existem muitas explicações que, para serem transformadas em predições, necessitariam do conhecimento do explanandum. Pode-se explicar o fato de um homem ter assassinado sua esposa, destacando seu ciúme em relação a ela. Mas, dificilmente, poderíamos prever o assassinato, mesmo conhecendo aquela característica do marido. De fato, precisaríamos saber que o ciúme era intenso o bastante para que chegasse a ocorrer o crime, mas só podemos conhecer isso depois do fato ocorrido (Scriven, 1959, p. 579). Este exemplo permite, talvez, um rebate mais fácil por parte de Hempel. Ele afirma que o exemplo não afeta o condicional de que uma explicação adequada poderia ter servido para prever o explanandum se a informação necessária para tal tivesse sido conhecida antes do evento. Observa, ainda, que Scriven não demonstra, em seus exemplos, que o tipo de fator que se precisa conhecer para a predição não possa sê-lo antes da ocorrência do evento-explanandum (Hempel, 1965, p. 371). Os exemplos apresentados até aqui, especialmente o da "paresia", desafiam a primeira subtese da simetria. Os ataques à primeira subtese em geral procuram mostrar que existem explicações genuínas que não servem para predições (no sentido hempeliano) e, assim, que a adequação ao modelo hempeliano não é condição necessária para o caráter explanatório. Aqui, entretanto, subscreveremos apenas as críticas à suficiência do modelo nomológico-dedutivo.

\section{A Insuficiência da Suficiência Nômica}

Um ataque à segunda subtese ameaça a suficiência do modelo. Pois, neste caso, estaremos diante de uma predição, nos moldes hempelianos, que não constitui potencialmente uma explicação. Hempel, de fato, considera a segunda subtese menos segura do que a primeira. Ele próprio mostra as dificuldades de se considerar que toda predição seja uma explicação potencial através do exemplo do sarampo. Um dos primeiros sintomas desta doença é o aparecimento de manchas esbranquiçadas na mucosa da boca, conhecidas como "Manchas de Koplik". O aparecimento delas é sempre seguido pelas outras manifestações do sarampo. Assim, estas poderiam ser preditas a partir daquelas. Tal correlação, entretanto, seria explicativa? Hempel admite que aqui pode haver dúvida, mas quando nos conta as suas razões para tal dúvida, dificilmente elas poderiam deixar de surpreender leitores das mais variadas inclinações. Diz:

Ainda este caso, e outros similares a ele, não constituem uma objeção decisiva contra a segunda subtese. Pois a relutância em considerar o aparecimento das manchas de Koplik como explanatório pode bem refletir dúvidas sobre se, como uma questão lei universal, aquelas manchas são sempre seguidas pelas manifestações posteriores do 
sarampo. Talvez uma inoculação com uma pequena quantidade do vírus do sarampo produzisse as manchas sem levar a um caso pleno de sarampo (...) a generalização de que as manchas de Koplik são sempre seguidas pelos sintomas posteriores do sarampo não expressariam uma lei e desse modo não poderiam propriamente suportar a explicação N-D correspondente (Hempel, 1965, p. 374-375, grifos meus).

O trecho mostra que Hempel se recusa até mesmo a fazer a distinção usual entre causa e sintoma ${ }^{5}$. As razões que podem motivar Hempel aqui são um tanto obscuras. Nós pensamos (e Hempel em seus momentos não-filosóficos também) as manchas de Koplik e os demais sintomas do sarampo como sendo efeitos comuns de uma mesma causa - a infecção virótica. Expondo em uma linguagem causal, duas alternativas parecem ser relevantes neste caso: a) as manchas de Koplik e os sintomas restantes podem ser efeitos de uma causa comum; b) as manchas de Koplik podem ser uma causa intermediária entre a infecção e os sintomas que aparecem após as manchas. Ora, se fizermos o teste proposto por Hempel, ou seja, se inocularmos uma pequena porção do vírus do sarampo e as manchas de Koplik aparecerem sem os sintomas posteriores, então saberemos que elas não são nomicamente suficientes para os sintomas posteriores. E atentemos que, para Hempel, apenas condições nomicamente suficientes são explanatórias. A reconstrução hempeliana para a causa é feita através de uma regularidade nômica, expressa por um condicional material, em que o antecedente é suficiente para o conseqüente e as condições antecedentes são anteriores no tempo ao explanandum. Em resumo, a causação é suficiência nômica mais prioridade temporal.

Voltando ao nosso exemplo, as duas situações descritas em (a) e (b) podem ser representadas, respectivamente, pelas figuras 1 e 2, como a seguir:

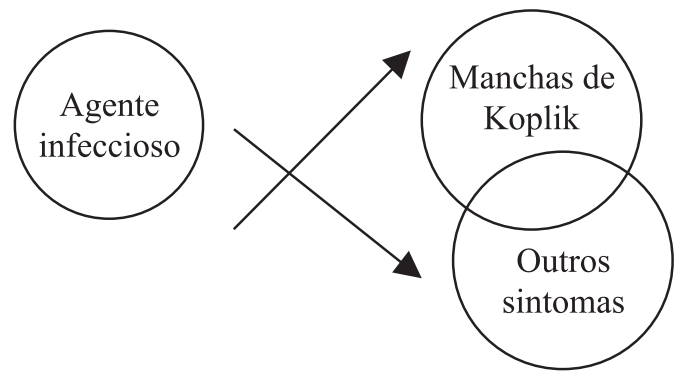

Fig. 1

5 Mesmo quando utiliza a expressão sintomas posteriores do sarampo, Hempel não dá ao conceito de sintoma um significado causal pleno. Ele, provavelmente, usa o termo apenas como uma comodidade estilística para não repetir a expressão manifestações posteriores do sarampo. A distinção entre causa e sintoma é de grande importância em medicina e, de certa forma, foi absorvida pelo senso comum. 


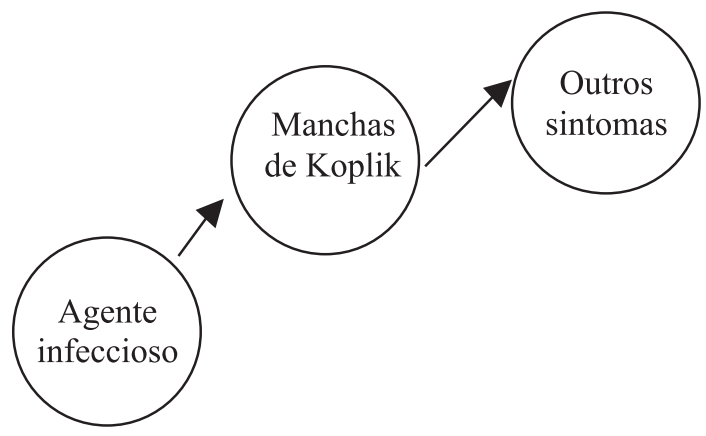

Fig. 2

Ainda mantendo uma linguagem abertamente causal, precisamos pensar o que acontece se enfraquecemos a causa, a infecção virótica, da maneira sugerida por Hempel. Podemos pensar que a situação causal é semelhante à que encontramos na Figura 1: as manchas de Koplik e as demais manifestações do sarampo são efeitos colaterais de uma mesma causa. Neste caso, de fato, não aceitamos que haja conexão explanatória entre as manchas e as demais manifestações do sarampo, mesmo que haja suficiência nômica entre elas. Por outro lado, podemos imaginar a situação como aquela apresentada na Figura 2, em que as manchas de Koplik funcionam como uma causa intermediária; o enfraquecimento do agente infeccioso poderia levar a um enfraquecimento da causa intermediária, evitando o aparecimento das demais manifestações. Estaríamos, contudo, dispostos, nesta situação, a considerar as manchas de Koplik, mesmo não sendo suficientes, como fator explanatório genuíno das demais manifestações (quando elas ocorressem), ainda que a considerássemos uma explicação mais superficial do que a que citasse a infecção virótica como fator causal - conclusão contrária a Hempel. Em suma, no caso representado na Figura 1, podemos ter suficiência nômica sem termos de fato uma explicação. Em contrapartida, no caso ilustrado na Figura 2, podemos não ter suficiência nômica e ainda assim termos uma explicação. O segundo caso, incidentalmente, conforme já discutido na seção anterior, lança dúvida sobre a necessidade de que uma explicação se adéqüe ao modelo hempeliano.

A exigência hempeliana de que uma explicação indique uma condição nomicamente suficiente para o explanandum não permite discriminar entre as alternativas mostradas em cada uma das figuras, constituindo um defeito bastante grave. Não saberíamos, por exemplo, se uma intervenção para prevenir as manchas de Koplik seria efetiva para evitar as outras manifestações do 
sarampo. Para sabermos onde intervir, temos de conhecer o mapa das relações causais, e este conhecimento é fundamental para explicarmos um evento. Regularidades que incorporem condições nomicamente suficientes são um instrumento grosseiro para aferir relações causais e explanatórias. Na citação anterior, Hempel fala dos sintomas posteriores do sarampo, em desacordo com o uso corrente da palavra. Quando falamos de sintomas, significamos, em parte, efeitos colaterais de uma doença, sem valor explanatório. Assim, Hempel sacrifica a distinção, cara à medicina, entre sintomas e causas. Sua teoria uniformiza várias distinções causais, reduzindo-as à suficiência nômica.

No balanço final, Hempel considera a segunda subtese, de que toda predição seja potencialmente uma explicação, uma questão aberta. Devemos atentar, entretanto, que isso não se deve aos problemas discutidos acima, em torno do exemplo do sarampo. Com relação a predições baseadas em condições nomicamente suficientes, vimos que Hempel, na verdade, endossa a segunda subtese. Toda a hesitação do nosso filósofo se deve à possibilidade, aventada por Scheffler e Scriven, de que existam formas de predição que não sejam baseadas em leis gerais, revelando-se, portanto, incapazes de serem convertidas em uma explicação N-D (Hempel, 1965, p. 375-376) ${ }^{6}$. Nosso interesse, porém, foi o de examinar se há simetria entre predições e explicações nomicamente baseadas.

\section{A $2^{\text {a }}$ Tese da Simetria}

Neste ponto, discutiremos alguns dos contra-exemplos clássicos ao modelo nomológico-dedutivo, avaliando sua força contra a teoria hempeliana. Antes, contudo, devemos nos posicionar quanto à função dos contra-exemplos na avaliação de teorias filosóficas. Acreditamos que teorias filosóficas, quando possível, devem ser confrontadas com os nossos juízos pré-filosóficos. Tais juízos refletem a maneira como determinamos o que cai sob um determinado conceito. Exemplifiquemos com o conceito de ciência. Todos conhecemos exemplos típicos de ciência: a física de Galileu e Newton, a química de Lavoisier, a teoria da evolução de Darwin etc. Também conhecemos casos que gostaríamos de deixar fora, como a astrologia, o vodu, a quiromancia etc. Uma boa teoria da ciência deve, em princípio, incluir os primeiros exemplos e excluir

6 Considerando a possibilidade de predições probabilísticas, Hempel diz: "As questões básicas em foco entre as diferentes concepções de inferência probabilística são ainda sujeitas a debate e investigação, e este ensaio não é o lugar para tentar uma avaliação plena de pontos de vista opostos. A segunda subtese portanto será considerada aqui como uma questão em aberto ". (Hempel,1965, p. 376). 
os últimos. Se a teoria não realizar esta segregação da forma indicada, bons motivos devem ser apresentados a título de compensação. Por exemplo, uma teoria sobre um certo conceito pode incluir casos indesejáveis e excluir casos desejáveis, mas oferecer vantagens, tais como simplicidade, aumento da capacidade de integração do conceito sob exame com outros conceitos, reduzindo-os a conceitos considerados mais fundamentais ou mais claros. Tais teorias podem sacrificar o atributo da adequação, refletindo mal as características pré-filosóficas do conceito. É claro que os nossos juízos préfilosóficos podem também ser corrigidos e melhorados pela teoria. Teremos de decidir, em cada caso, em que direção fazer os ajustes e as correções. Ainda que em outro contexto, falando sobre regras de inferência, Nelson Goodman sintetiza o espírito dos comentários feitos acima (Princípio Equilíbrio Reflexivo):

(...) inferências dedutivas são justificadas por sua conformidade com as regras gerais válidas, e (...) regras gerais são justificadas por sua conformidade com as inferências válidas. Este, porém, é um círculo virtuoso. O ponto é que as regras e as inferências particulares são justificadas por serem colocadas em mútuo acordo. A regra é corrigida se ela produz uma inferência que nós não desejamos aceitar; uma inferência é rejeitada se ela viola uma regra que não desejamos corrigir. O processo de justificação é um delicado processo de fazer ajustes mútuos entre regras e inferências aceitas; e no acordo realizado jaz a única justificação necessária para ambos (Goodman, 1954, p. 64).

Assim, exemplos e contra-exemplos serão levados a sério na avaliação de teorias. Não basta, entretanto, apenas exibir contra-exemplos a uma determinada teoria quando queremos criticá-la; é preciso usá-los para diagnosticar os erros da teoria criticada e apontar o caminho para as alternativas. Isso não contraria, entretanto, o fato de que a exibição de contra-exemplos seja parte importante de uma avaliação mais profunda de uma teoria filosófica.

\section{O Mastro e o Pêndulo}

Comecemos pelo mais famoso dos exemplos, hoje já clássico, da sombra do mastro (ficou conhecido na literatura simplesmente como Flagpole). Inicialmente proposto por Sylvain Bromberger ${ }^{7}$, o exemplo tem sido recorrentemente discutido na literatura sobre explicação. O problema que apresenta é realmente fecundo e fonte de importantes insights sobre as questões que ora nos preocupam. 
Em uma primeira formulação, o exemplo pode ser descrito da seguinte maneira: suponhamos um certo mastro, iluminado pelo sol, que lança sua sombra no chão. Supondo como uma lei o fato de que a luz viaja em linha reta, podemos, a partir da altura do mastro $(h)$ e da inclinação dos raios solares (q), calcular a comprimento da sombra $(s)$. Este cálculo, capaz de ser colocado na forma de uma dedução, pode ser aceito como uma resposta à pergunta "por que tal mastro possui uma sombra de tal tamanho?". Podemos, também, a partir do comprimento da sombra e da inclinação dos raios solares, calcular a altura do mastro. Este cálculo, porém, não parece ser uma resposta adequada à pergunta “por que este mastro possui tal altura?". Ambos os cálculos, entretanto, se adéquam ao modelo nomológico-dedutivo, sendo considerados explicações legítimas segundo este modelo (ver Salmon et al, 1992, p. 21). Isso nos coloca diante de alguns problemas.

Hempel (1965) declara, explicitamente, que explicações podem ser consideradas como respostas a questões do tipo "por que ...?". No caso do exemplo acima, é difícil ver como colocá-lo no pretendido formato. A altura do mastro poderia responder a uma pergunta do tipo "Dados o comprimento da sombra (do mastro) e a elevação do sol, qual é a altura do referido mastro?". No mínimo, deveríamos perguntar por que razão a formulação é diferente neste caso. Podemos conceder, em consideração ao argumento, que a ligação entre explicações e questões do tipo "por que...?" é de importância secundária. Neste caso, teríamos uma concepção técnica do conceito de explicação, reduzindo-o a um argumento dentro do padrão nomológico-dedutivo. Isto é, o conceito ordinário de explicação estaria sendo substituído por um outro, mais técnico. Uma explicação seria uma espécie de cálculo em que podemos perceber a relação entre eventos ou entre seus aspectos, e isto pode se dar em qualquer direção. Note-se que, neste exemplo, seria estranho dizer que podemos predizer a altura do mastro devido à falta de clareza nas relações temporais. O que vem antes e o que vem depois? Não é claro se estamos diante de uma regularidade de sucessão ou de coexistência. Para Hempel, apenas regularidades de sucessão podem ser causais, e uma explicação causal é aquela em que as condições particulares são, temporalmente, anteriores ao explanandum. A tese da simetria entre explicação e predição, discutida anteriormente, se aplicaria particularmente a esta espécie de explicação.

Para regularidades de coexistência, contudo, fica evidente uma outra espécie de simetria (poderíamos chamá-la de $2^{a}$ Tese da Simetria): aquela que permite a permutação entre parte do explanans e o explanandum. Esta permutação pode ocorrer também na explicação causal, embora Hempel seja ambíguo neste caso. Por exemplo, podemos dar uma explicação causal da 
posição de um dado planeta a partir de sua posição em um instante anterior (mais as leis pertinentes), mas também podemos calcular a posição do planeta no instante anterior a partir de sua posição em um instante posterior. Neste caso, teríamos uma explicação? Seria ela de natureza não-causal? Hempel hesita. Em 1962, ele usa o termo retrodição (e não explicação) para o último caso que descrevemos. Ele utiliza a expressão sistematização dedutivonomológica para incluir predição, explicação e retrodição (Hempel, 1962, p. 99). Em seu mais extenso texto sobre a explicação, Hempel diz:

\begin{abstract}
Qualquer desconforto em explicar um evento por referência a fatores que incluem ocorrências posteriores poderia se originar da idéia de que explicações do tipo mais familiar, tais como nossos exemplos anteriores, parecem exibir o eventoexplanandum como tendo sido produzido por ocorrências anteriores; ao passo que nenhum evento pode ser dito produzido por fatores que nem mesmo tinham se realizado ao tempo da ocorrência dele. Talvez esta idéia também pareça lançar dúvida sobre as supostas explicações por referência a circunstâncias simultâneas. Porém, enquanto tais considerações podem bem fazer nossos exemplos anteriores de explicação, e todas as explicações causais parecerem mais naturais e plausíveis, não é claro que construção precisa poderia ser dada à noção de fatores que "produzem" um dado evento e que razão haveria para negar o status de explicação a todos os relatos invocando ocorrências que são posteriores ao evento a ser explicado (Hempel, 1965, p. 353-354).
\end{abstract}

Um passo além, em sua obra menos técnica intitulada Philosophy of Natural Science, ele não fala mais simplesmente de explicação, mas de explicações nomológico-dedutivas para se referir a toda explicação por subsunção dedutiva sob leis gerais (Hempel, 1966, p. 70). No final, ficamos com a estranha sensação de que tudo está reduzido a uma disputa terminológica. Realmente há um recuo estratégico do autor ao longo dos anos. Ele reivindica menos para as suas teorias, mas nunca diz o que havia de errado com suas posições anteriores.

O que parece acontecer aqui é o seguinte: como as regularidades de coexistência possuem simetria temporal, Hempel sente-se mais à vontade para descolar seu modelo de qualquer condição objetiva não-lógica. Quando estamos diante de regularidades de sucessão, Hempel sente que, de alguma forma, o tempo deveria ser levado em consideração, daí o seu escrúpulo em chamar uma retrodição de explicação. Em suas obras, ele quase sempre dá algum destaque às chamadas explicações causais, embora a tendência de seu pensamento maduro seja a diluição total da importância desta categoria. Isso pode ser visto na citação anterior, em que ele considera as diferenças temporais de pequena importância para o status explanatório e, finalmente, na sua atitude de utilizar a expressão técnica explicação $N-D$. O que parece ser o lema final 
de Hempel é algo como não interessa se temos regularidades de sucessão ou de coexistência, uma explicação nada mais é do que a subsunção nômica de eventos $^{8}$. Talvez, se ele tivesse percebido como capturar a assimetria causal sem utilizar o tempo, as coisas fossem diferentes.

De fato, está longe de ser claro por que uma diferença temporal pode contribuir para o caráter explanatório. Se tivéssemos, entretanto, uma explicação da assimetria causal que não dependesse essencialmente do tempo, poderíamos ter o seguinte lema: não importa se temos regularidades de sucessão ou regularidades de coexistência, podemos ainda buscar explicações especificamente causais em cada caso. Não pretendemos que o nosso lema seja exato, apenas o avançamos para realçar o contraponto a Hempel. Antes de tudo, devemos lembrar que estamos lidando com explicações de eventos singulares e seus aspectos, coincidindo com o escopo da teoria hempeliana. Mesmo com esta restrição, não afirmamos que toda explicação de fatos singulares seja causal. Explicações do todo por suas partes (mereológicas), explicações de identidade (que não envolvem existências distintas), explicações que supõem as assim chamadas determinações do tipo Cambridge $e^{9}$ "Xantipa tornou-se uma viúva porque Sócrates morreu"), para citar apenas algumas, parecem ser todas explicações não-causais (ver Kim, 1974). O que queremos avançar é o seguinte: quando supomos existir uma relação causal envolvida em um certo contexto, uma explicação dentro deste contexto deve refletir as características fundamentais daquela relação. No exemplo do mastro, a dimensão fundamental desconsiderada por Hempel é a direcionalidade (ou assimetria) da causação. Neste caso, tratado por Hempel como envolvendo coexistência, ainda poderíamos apontar uma diferença temporal na situação. Em conexão com isso, Salmon, por exemplo, diz:

À primeira vista, poderíamos estar inclinados a dizer que este é um caso de coexistência: o mastro e a sombra existem simultaneamente. Sob uma inspeção mais detida, entretanto, percebemos que um processo causal está envolvido e que a luz deve ou passar ou ser bloqueada pelo mastro antes de alcançar o chão onde a sombra é lançada (Salmon, 1998, p. 102).

8 Estamos atentos para as dificuldades de se passar de meras regularidades para regularidades nômicas. Mas este ponto não é importante aqui, pois, mesmo se supusermos que temos uma teoria satisfatória do nômico, os problemas discutidos permanecem.

9 Esta terminologia foi introduzida por Peter Geach em seu God and Soul (apud Kim, 1974). 
De fato, esta interpretação do exemplo é plausível e Hempel poderia aceitála, como é evidenciado em alguns de seus comentários ${ }^{10}$. Permanece, porém, a dúvida sobre se a prioridade causal é a prioridade temporal e sobre a relação desta última com o caráter explanatório. Em outras palavras, se a diferença entre a causa e o seu efeito é essencialmente temporal, o que diferenciaria a explicação do efeito pela causa da explicação da causa pelo efeito?

De qualquer forma, existem exemplos em que a diferença temporal não parece disponível. O caso clássico é o da relação entre o comprimento do pêndulo $(l)$ e o seu período $(T)$, em um dado campo gravitacional de aceleração $(g)$. Sobre este exemplo, Hempel também considera que tanto é possível explicar o período do pêndulo a partir de seu comprimento quanto o comprimento a partir do período (Hempel, 1962, p. 94-95). Estimamos que este exemplo seja grandemente reconfortante para Hempel, visto que a situação é simétrica em relação à única condição não-lógica pela qual ele tem algum respeito - o tempo. Assim, ele pode desafiar aqueles que insistem na intuição de que apenas o comprimento do pêndulo explica o seu período (e não vice-versa) a buscarem a fonte de tal assimetria explanatória. Ele parece não considerar que a prioridade causal pode não ser de natureza temporal e que, portanto, exista a possibilidade de causação em contextos de coexistência.

Este ponto é também interessante para mostrar como de um mesmo exemplo se pode tirar conclusões contrárias, dependendo do compromisso filosófico inicial. Hempel considera que a sucessão no tempo é a única coisa, além das regularidades, que pode entrar na noção de causação. Assim, o exemplo do pêndulo não cria problemas — simplesmente, não estaríamos diante de um caso de causação. Entretanto, alguém que reconheça existir, neste caso, uma assimetria explanatória pode ser motivado a buscar uma teoria nãotemporal para explicar a assimetria causal e, dessa forma, prover a base para a assimetria em um certo tipo de explicação. Um caminho alternativo consiste em desconectar causação e explicação, buscando alhures a fonte da assimetria desta, por exemplo, em aspectos pragmáticos de nossas explicações. O exame desta alternativa, porém, ficará para outra ocasião.

Finalmente, gostaríamos de examinar um argumento especioso que Hempel avança para defender a sua posição. Referindo-se ao caso do pêndulo, ele diz que, se pensamos normalmente que a explicação é válida apenas em uma direção, é porque supomos, equivocadamente, que podemos alterar o período

10 "Dependendo do contexto em que é levantada, a demanda por uma explicação poderia reclamar aqui por alguma espécie de relato causal de como o mastro veio a ter esta altura (...). Um relato desta espécie seria de novo um caso especial de explicação causal, invocando entre as condições antecedentes certas disposições dos agentes envolvidos na construção do mastro " (Hempel, 1962, p. 95). 
do pêndulo por meio da alteração de seu comprimento, mas não vice-versa. Contra isso, ele argumenta que, se a localização do pêndulo permanece fixa e, portanto, a aceleração gravitacional $(g)$, nós podemos alterar o comprimento do pêndulo alterando o seu período. Para tanto, basta alterarmos o período, modificando primeiro o comprimento do pêndulo e, dessa forma, trivialmente, alterando o seu comprimento. Se $g$ permanece constante, qualquer alteração em $l$ supõe uma alteração em $T$, e vice-versa (Hempel, 1962, p. 94; e 1965, p. 352-353). Este espantoso argumento, entretanto, é vulnerável se não supusermos $g$ constante. De fato, se $g$ não é constante, uma alteração em $T$ supõe apenas uma alteração em $g$ ou $l$. Podemos, perfeitamente, supor que $T$ se alterou e $l$ permaneceu constante. Hempel poderia tentar restaurar a simetria, apontando para o fato de que podemos também alterar $l$ mantendo $T$ constante. Neste caso, teríamos que supor que as variáveis $g$ e $l$ são, correlacionadas de forma que a variação em uma é compensada pela variação da outra. Ocorre, porém, que nós naturalmente pensamos que as variáveis $l$ e $g$ são independentes, isto é, não-correlacionadas (ver Hausman, 1998). Assim, a compensação não ocorre e o argumento de Hempel falha. Hempel precisaria, então, de um argumento para mantermos $g$ fixa ou para supormos que $l$ e $g$ não são independentes ${ }^{11}$. Tanto quanto sabemos, o texto de Hempel não supre tal demanda. $\mathrm{O}$ ônus da prova, então, fica com os hempelianos.

\section{Referências}

BROMBERGER, S. Why-Questions. In: COLODNY (Ed.). Mind and Cosmos: Essays in Contemporary Science and Philosophy. University of Pittsburgh Press, Pittsburgh, 1966.

GOODMAN, N. [1954]. Fact, Fiction, and Forecast. Cambridge: Harvard University Press, 1983.

HAUSMAN, D. M. Causal Asymmetries. Cambridge: Cambridge University Press, 1998.

HEMPEL, C. G. [1962]. Deductive-Nomological versus Statistical Explanation. In: FETZER (Ed.). The Philosophy of Carl G. Hempel. Oxford: Oxford University Press, 2001.

[1966]. Filosofia da Ciência Natural. Rio de Janeiro: Zahar Editores, 1970. . Aspects of Scientific Explanation. In: HEMPEL, C. G. Aspects of Scientific Explanation and the Others Essays in the Philosophy of Science. New York: The Free Press, 1965.

11 É claro que podemos introduzir algum mecanismo que crie uma correlação entre l e g, mas, neste caso, mudamos a estrutura causal. A estrutura causal assim criada tem novas variáveis e diferentes relações entre elas. 
KIM, J. [1974]. Noncausal Connections. In: KIM, J. Supervenience and Mind. Cambridge: Cambridge University Press, 1993.

RUBEN, D. H.. Explaining Explanation. London: Routledge, 1990.

SALMON, W. C. Causality and Explanation. Oxford: Oxford University Press, 1998. SALMON, W. C. et al. [1992]. Introduction to Philosophy of Science. Indianapolis: Hackett Publishing Company, 1999.

SCRIVEN, M. [1959]. Os truísmos como bases das explicações históricas. In: GARDINER, P. (Ed.). Teorias da História. Lisboa: Fundação Calouste Gulbenkian, 1984. 